\title{
Article
}

\section{A model of solid-solution interactions in acid organic soils, based on the complexation properties of humic substances}

Tipping, E. and Hurley, Margaret Anne

Available at http://clok.uclan.ac.uk/17449/

Tipping, E. and Hurley, Margaret Anne ORCID: 0000-0002-2502-432X (1988) A model of solid-solution interactions in acid organic soils, based on the complexation properties of humic substances. Journal of Soil Science, 39 (4). pp. 505-519. ISSN 2231-6833

It is advisable to refer to the publisher's version if you intend to cite from the work. http://dx.doi.org/10.1111/j.1365-2389.1988.tb01235.x

For more information about UCLan's research in this area go to http://www.uclan.ac.uk/researchgroups/ and search for <name of research Group>.

For information about Research generally at UCLan please go to http://www.uclan.ac.uk/research/

All outputs in CLoK are protected by Intellectual Property Rights law, including Copyright law. Copyright, IPR and Moral Rights for the works on this site are retained by the individual authors and/or other copyright owners. Terms and conditions for use of this material are defined in the policies page. 


\title{
A model of solid-solution interactions in acid organic soils, based on the complexation properties of humic substances
}

\author{
E. TIPPING \& M. A. HURLEY \\ Freshwater Biological Association, The Ferry House, Ambleside, Cumbria LA22 OLP, UK
}

\begin{abstract}
SUMMARY
CHAOS (Complexation by Humic Acids in Organic Soils) is a quantitative chemical model of organic soils that incorporates complexation by the functional groups of humic substances and non-specific ion-exchange reactions. The two types of interaction are linked by the net humic charge, $Z$, which depends on the extents of proton and metal complexation, and which in turn determines ionic concentrations in the diffuse part of the electrical double layer, by a Donnan equilibrium. CHAOS was found to account satisfactorily for the results of acid-base titration experiments ( $\mathrm{pH}$ range 3-5) with soil samples, giving reasonable simultaneous predictions of solution $\mathrm{pH}$ and concentration of $\mathrm{Al}^{3+}$. Predictive calculations with CHAOS suggest that organic soils acidified by acid rain would respond on a time-scale of years-to-decades to reductions in rain acidity. An associated effect might be an increase in the concentration of dissolved organic matter in the soil solution.
\end{abstract}

\section{INTRODUCTION}

In the upper horizons of acid soils, solution composition is determined primarily by interactions between dissolved species and solid organic matter (Krug \& Frink, 1983; Bache, 1984). The interactions involve $\mathrm{H}^{+}, \mathrm{Al}^{3+}, \mathrm{AlOH}^{2+}, \mathrm{Ca}^{2+}, \mathrm{Mg}^{2+}, \mathrm{Na}^{+}$and $\mathrm{K}^{+}$in solution, and humic $\mathrm{COOH}$ and weaker acid groups, together with non-specific cation-exchange sites, in the solid phase. Their quantitative description would be useful in understanding (a) the effects of acid deposition, (b) podzolization, and (c) how the organic content of drainage waters is determined. The last is important to the Water Industry because of the need to remove 'dissolved colour' before water is acceptable for domestic supply.

In this paper we present a quantitative model of acid organic soils, based on the complexation properties of humic substances (HS), the dominant soil ingredients with respect to interactions with the aqueous phase. The soil is treated as a concentrated suspension of HS. Complexation reactions are described by combinations of intrinsic equilibrium constants and electrostatic terms, nonspecific cation-exchange by a Donnan equilibrium. The two types of reaction are linked via $Z$, the net humic charge. The model is based on a previous one for HS in natural waters (Tipping et al., 1988a) and is referred to as CHAOS (Complexation by Humic Acids in Organic Soils). Firstly, the formulation of CHAOS is described, next its ability to account for the results of experiments with soil suspensions is considered, and lastly its use for predictive modelling is explored.

\section{MODEL FORMULATION}

A schematic diagram of the reactions involved in CHAOS is given in Fig. 1. Cationic species (restricted to $\mathrm{H}^{+}, \mathrm{Al}^{3+}, \mathrm{AlOH}^{2+}, \mathrm{Ca}^{2+}$ and $\mathrm{Na}^{+}$for ease of presentation) occur in three compartments, $H, D$ and $S$. Compartment $H$ is the humic material itself, able to form complexes with the 


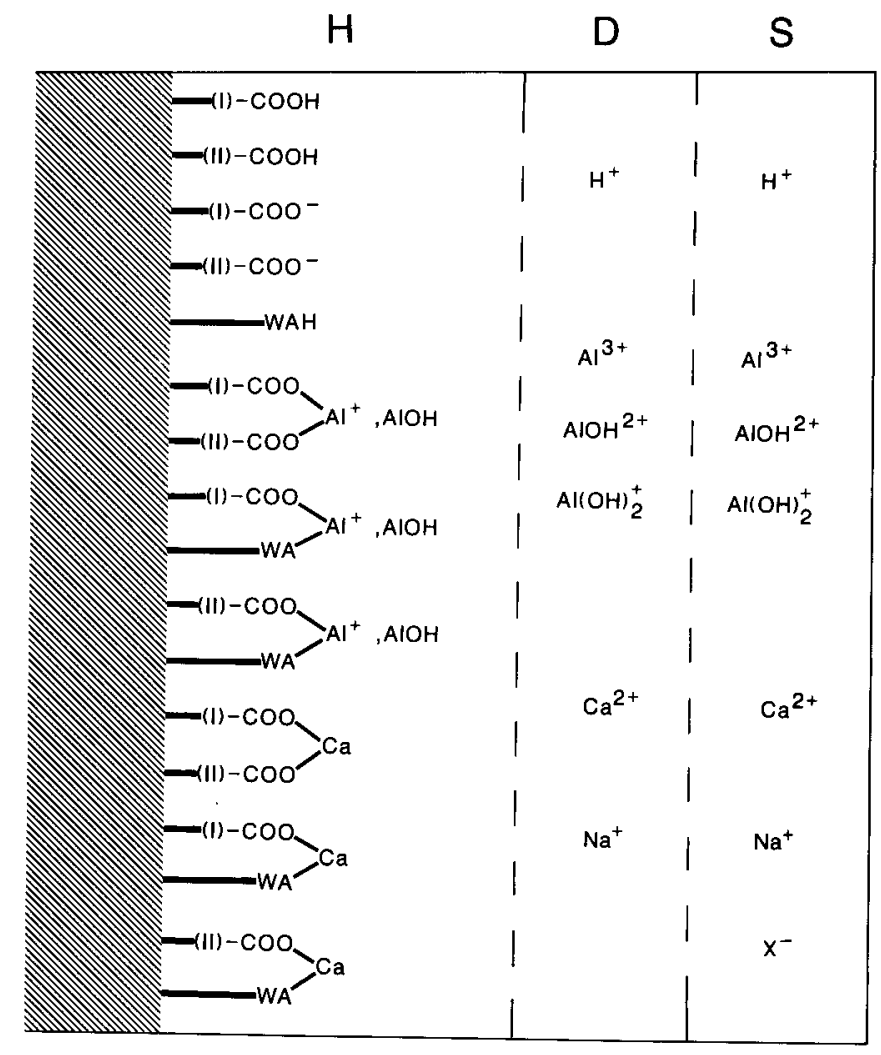

Fig. 1. Species considered in CHAOS.

cations. In compartment $D$, the diffuse part of the electrical double layer, cations are held purely by electrostatic attraction to the (net) negatively charged HS. Compartment $S$ is the bulk solution. Two charge balances are required to describe this situation: the net charge of compartments $H$ and $D$ is zero, as is that of compartment $S$, where cationic charge is balanced by non-interacting (strong acid) anions, designated by $\mathrm{X}^{-}$. In the model the concentration of HS is expressed in terms of the volumes of the aqueous compartments $D$ and $S$, so that a concentration of $x \mathrm{~g} \mathrm{HS}^{-1}$ means that for every $x \mathrm{~g}$ of HS, compartments $D$ and $S$ together occupy a volume of 11 . For each litre of $(D+S)$ there are $V_{D}$ litres of $D$ and $V_{S}$ litres of $S$, so that $V_{D}+V_{S}=1$.

Complexation by HS is accounted for in CHAOS as in model III of Tipping et al. (1988a). That paper should be consulted for details; the following is a brief account. Contents of humic complexing groups are chosen on the basis of published information (Thurman, 1985), simplification being introduced to make it possible to incorporate competitive interactions reasonably easily. The HS are assumed to have two types of carboxyl group, I and II, both of which undergo dissociation at $\mathrm{pH} \leqslant 7$. In addition there are weaker acid groups (WAH) that dissociate only at higher $\mathrm{pH}$ values, but which can exchange a proton for a metal ion at $\mathrm{pH} \leqslant 7$. These $\mathrm{WAH}$ groups would include, for example, weak $\mathrm{COOH}$ groups and phenolic $\mathrm{OH}$ groups. The metal ions $\mathrm{Al}^{3+}, \mathrm{AlOH}^{2+}$ and $\mathrm{Ca}^{2+}$ bind at bidentate sites of three types: type A consists of a type I COOH and a type II COOH, type BI of a type I COOH and a WAH, type BII of a type II COOH and a WAH. Previous work (Tipping $e t$ al., 1988a) has shown that this suite of complexed species is the simplest formulation that can account for the competitive interactions involved. For example, if only one type of $\mathrm{COOH}$ group is assumed it is not generally possible to fit proton binding data obtained in the absence of $\mathrm{Al}$ or $\mathrm{Ca}$.

The HS are characterized by a total acidity, $A c$ (eq $\mathrm{g}^{-1}$ ), which is the sum of the $\mathrm{COOH}$ and WAH groups. Estimation of total humic acidity is not straightforward (Perdue, 1985), and even if an 
accurate value can be obtained there is no guarantee that all the ionizable groups will be able to participate in metal and proton binding at environmentally-relevant $\mathrm{pH}$ values. In our studies (Tipping et al., 1988a) we estimated $A c$ by titration to the arbitrarily chosen $\mathrm{pH}$ of 11.5 , and the values obtained are best regarded as first approximations to the true (effective) values. In datafitting the model it is found that the estimate of the content of carboxyl groups $\left(n, \mathrm{eq}^{-1}\right)$ has a small

Table 1. Intrinsic and charge-dependent equilibrium constants

$$
\begin{aligned}
& K_{\mathrm{I}}=\frac{\left[(\mathrm{I})-\mathrm{COO}^{-}\right]\left\{\mathrm{H}^{+}\right\}}{[(\mathrm{I})-\mathrm{COOH}]} \quad K_{\mathrm{I}}(Z) \quad=K_{\mathrm{I}} \mathrm{e}^{2 \omega \mathrm{Z}} \\
& K_{\mathrm{II}}=\frac{\left[(\mathrm{II})-\mathrm{COO}^{-}\right]\left\{\mathrm{H}^{+}\right\}}{[(\mathrm{II})-\mathrm{COOH}]} \quad K_{\mathrm{II}}(\mathrm{Z}) \quad=K_{\mathrm{II}} \mathrm{e}^{2 \mathrm{iw} Z} \\
& K_{\mathrm{A}, \mathrm{A} 1}=\frac{\left[\begin{array}{l}
(\mathrm{I})-\mathrm{COO} \backslash \mathrm{Al}^{+} \\
(\mathrm{II})-\mathrm{COO}
\end{array}\right]\left\{\mathrm{H}^{+}\right\}^{2}}{[(\mathrm{I})-\mathrm{COOH}][(\mathrm{II})-\mathrm{COOH}]\left\{\mathrm{Al}^{3+}\right\}} K_{\mathrm{A}, \mathrm{Al}}(\mathrm{Z})=K_{\mathrm{A}, \mathrm{Al}} \mathrm{e}^{-2 w Z} \\
& K_{\mathrm{Bl}, \mathrm{Al}}=\frac{\left[\begin{array}{c}
(\mathrm{I})-\mathrm{COO} \\
\left.\mathrm{WA}-\mathrm{Al}^{+}\right]\left\{\mathrm{H}^{+}\right\}^{2}
\end{array}\right.}{[(\mathrm{I})-\mathrm{COOH}][\mathrm{WAH}]\left\{\mathrm{Al}^{3+}\right\}} K_{\mathrm{Bl}, \mathrm{Al}}(Z)=K_{\mathrm{Bl}, \mathrm{Al}} \mathrm{e}^{-2 w Z} \\
& K_{\mathrm{BI}, \mathrm{Al}}=\frac{\left[\begin{array}{c}
(\mathrm{II})-\mathrm{COO} \\
\mathrm{WA}-\mathrm{Al}^{+}
\end{array}\right]\left\{\mathrm{H}^{+}\right\}^{2}}{[(\mathrm{II})-\mathrm{COOH}][\mathrm{WAH}]\left\{\mathrm{Al}^{3+}\right\}} K_{\mathrm{BI}, \mathrm{Al}}(Z)=K_{\mathrm{BII}, \mathrm{Al}} \mathrm{e}^{-2 W Z} \\
& K_{\mathrm{Al}, \mathrm{H}}=\frac{\left[\begin{array}{c}
\sim \\
\mathrm{AlOH}
\end{array}\right]\left\{\mathrm{H}^{+}\right\}}{\left[\mathrm{Al}^{+}\right]} K_{\mathrm{Al}, \mathrm{H}}(Z)=K_{\mathrm{Al}, \mathrm{H}} \mathrm{e}^{2 \omega Z Z} \\
& K_{\mathrm{A}, \mathrm{Ca}}=\frac{\left[\begin{array}{l}
(\mathrm{I})-\mathrm{COO}-\mathrm{Ca} \\
(\mathrm{II})-\mathrm{COO}-\left\{\mathrm{H}^{+}\right\}^{2}
\end{array}\right.}{[(\mathrm{I})-\mathrm{COOH}][(\mathrm{II})-\mathrm{COOH}]\left\{\mathrm{Ca}^{2+}\right\}} K_{\mathrm{A}, \mathrm{Ca}}(\mathrm{Z})=K_{\mathrm{A}, \mathrm{Ca}} \\
& K_{\mathrm{BL}, \mathrm{Ca}}=\frac{\left[\begin{array}{c}
(\mathrm{I})-\mathrm{COO}-\mathrm{Ca} \\
\mathrm{WA}-\left\{\mathrm{H}^{+}\right\}^{2}
\end{array}\right.}{[(\mathrm{I})-\mathrm{COOH}][\mathrm{WAH}]\left\{\mathrm{Ca}^{2+}\right\}} K_{\mathrm{BI}, \mathrm{Ca}}(\mathrm{Z})=K_{\mathrm{Bl}, \mathrm{Ca}} \\
& K_{\mathrm{BI}, \mathrm{Ca}}=\frac{\left[\begin{array}{c}
(\mathrm{II})-\mathrm{COO}-\mathrm{Ca} \\
\mathrm{WA}-\left\{\mathrm{H}^{+}\right\}^{2}
\end{array}\right.}{[(\mathrm{II})-\mathrm{COOH}][\mathrm{WAH}]\left\{\mathrm{Ca}^{2+}\right\}} K_{\mathrm{BI}, \mathrm{Ca}}(\mathrm{Z})=K_{\mathrm{BH}, \mathrm{Ca}}
\end{aligned}
$$


error associated with it, so that uncertainty in $A c$ translates to uncertainty in the content of weak acid groups. Since these are modelled in a very rudimentary way, i.e. by assuming them all to be the same, it is probable that uncertainty in their abundance is a minor problem at this stage of model development. The parameter $A c$ is also used as an adjustable parameter for 'rescaling' the model to fit field results for natural waters (Tipping et al., 1988b), or, as in this work, to fit laboratory results for soil samples (see below). The content of $\mathrm{COOH}$ groups $(n)$ consists of $n / 2$ type I groups and $n / 2$ type II groups. It follows that of the total content of bidentate (metal-binding) sites, $A c / 2$, there are $n-(A c / 2)$ type A groups, $(A c-n) / 2$ type BI groups, and $(A c-n) / 2$ type BII groups, per $\mathrm{g} \mathrm{HS}$.

Relationships between complexed ions and ions in the bulk solution (compartment $S$ ) are given by expressions that combine an intrinsic equilibrium constant with terms accounting for the electrostatic attraction or repulsion between the humic binding site and the ion in solution. The latter have the general form $\exp \left(-2 w z_{\mathrm{i}} Z\right)$ where $w$ is the 'electrostatic interaction factor', $z_{\mathrm{i}}$ is the charge of the ion in question, and $Z$ is the net humic charge (cf. Tanford, 1961). Consider for example the reaction

$$
\text { (I)- } \mathrm{COOH} \rightleftharpoons(\mathrm{I})-\mathrm{COO}^{-}+\mathrm{H}^{+}
$$

The equilibrium constant for the (hypothetical) case where there is no electrostatic influence-the intrinsic equilibrium constant-is given by

$$
K_{1}=\frac{\left[(\mathrm{I})-\mathrm{COO}^{-}\right]\left\{\mathrm{H}^{+}\right\}}{[(\mathrm{I})-\mathrm{COOH}]}
$$

where square and curled brackets indicate concentration and activity, respectively. The (chargedependent) equilibrium constant for the case where the HS have a net charge of $Z \mathrm{eq}^{-1}$ is given by

$$
K_{\mathrm{I}}(Z)=\frac{\left[(\mathrm{I})-\mathrm{COO}^{-}\right]\left\{\mathrm{H}^{+}\right\}}{[(\mathrm{I})-\mathrm{COOH}] \exp (-2 w Z)}=K_{\mathrm{I}} \exp (2 w Z)
$$

Since $w$ is positive and $Z$ invariably negative, the charge-dependent constant is less than the intrinsic one, in this case. In other words, the $\mathrm{COOH}$ group is less dissociated, reflecting the attraction of the negatively-charged humic molecule for $\mathrm{H}^{+}$. Table 1 gives expressions for all the complexation reactions that occur in CHAOS. The nine equilibrium constants shown are condensed to five by making the simplifying assumption that

$$
\begin{aligned}
& K_{\mathrm{A}, \mathrm{Al}}=K_{\mathrm{BI}, \mathrm{Al}}=K_{\mathrm{BII}, \mathrm{Al}}=K_{\mathrm{Al}} \\
& K_{\mathrm{A}, \mathrm{Ca}}=K_{\mathrm{BI}, \mathrm{Ca}}=K_{\mathrm{BII}, \mathrm{Ca}}=K_{\mathrm{Ca}}
\end{aligned}
$$

It should be noted that the reactions to which these equilibrium constants refer are formulated as proton-metal exchanges (Table 1), not as ionized ligand-metal associations. Some justification for the assumption of a single constant comes from literature data for simple diprotic acids that correspond to the assumed humic bidentate sites. Thus from Martell \& Smith (1977) the following equilibrium constants (at $25^{\circ} \mathrm{C}$, zero ionic strength) for the exchange reaction $\mathbf{L H}_{2}+\mathrm{Al}^{3+} \rightleftharpoons \mathrm{LAl}^{+}+2 \mathrm{H}^{+}$(where $\mathrm{L}^{2-}$ is the unprotonated ligand) can be calculated; phthalic acid $10^{-4.0}$, meso-tartaric acid $10^{-1.3}$, salicylic acid $10^{-2.9}$, sulphosalicylic acid $10^{-1.4}$. Equilibrium constants for the association reaction $\mathrm{L}^{2-}+\mathrm{Al}^{3+} \rightleftharpoons \mathrm{LAl}^{+}$vary much more widely, having values of $10^{4.3}, 10^{6.7}, 10^{14.0}$ and $10^{13.4}$, respectively. Values of $K_{\mathrm{A} \text { f }}$ for four humic samples were in the range $10^{-3.3}-10^{-3.8}$ (Tipping et al., 1988a), similar to those for the simple diprotic acids.

The electrostatic interaction factor, $w$, is given by the empirical equation

$$
w=P \log _{10}(I) \exp (Q|Z|)
$$

where $P$ and $Q$ are constants, $I$ is the ionic strength and $|Z|$ is the modulus of $Z$. It is Equation (6) that takes the effect of ionic strength on humic complexation reactions into account.

Relationships between ionic concentrations in compartments $D$ and $S$ are accounted for in the simplest possible way by assuming a Donnan equilibrium (Arnold, 1978). Thus for two cations $\mathrm{Y}_{1}{ }^{\mathrm{m}+}$ and $\mathrm{Y}_{2}{ }^{\mathrm{n}+}$ we have

$$
\left(\left\{\mathrm{Y}_{1}^{\mathrm{m}+}\right\}_{D} /\left\{\mathrm{Y}_{1}^{\mathrm{m}+}\right\}_{S}\right)^{\mathrm{l} / \mathrm{m}}=\left(\left\{\mathrm{Y}_{2}^{\mathrm{n}+}\right\}_{D} /\left\{\mathrm{Y}_{2}^{\mathrm{n}+}\right\}_{S}^{1 / \mathrm{n}}\right.
$$


It is further assumed that activity coefficients in the two compartments are the same, so that

$$
\begin{aligned}
\left(\left[\mathrm{Na}^{+}\right]_{D} /\left[\mathrm{Na}^{+}\right]_{S}\right) & =\left(\left[\mathrm{H}^{+}\right]_{D} /\left[\mathrm{H}^{+}\right]_{S}\right) \\
& =\left(\left[\mathrm{Ca}^{2+}\right]_{D} /\left[\mathrm{Ca}^{2+}\right]_{S}\right)^{\frac{1}{2}} \\
& =\left(\left[\mathrm{Al}^{3+}\right]_{D} /\left[\mathrm{Al}^{3+}\right]_{S}\right)^{\frac{1}{3}} \\
& =\left(\left[\mathrm{AlOH}{ }^{2+}\right]_{D} /\left[\mathrm{AlOH}{ }^{2+}\right]_{S}\right)^{\frac{1}{2}} \\
& =\left(\left[\mathrm{Al}(\mathrm{OH})_{2}^{+}\right]_{D} /\left[\mathrm{Al}(\mathrm{OH})_{2}^{+}\right]_{S}\right)
\end{aligned}
$$

To calculate the concentrations of the different species in the three compartments, the equations given above were combined with mass-balance relationships for $\mathrm{Al}, \mathrm{Ca}, \mathrm{Na}$ and $\mathrm{HS}$ (cf. Tipping $e t$ $a l ., 1988 \mathrm{a})$. Iterative procedures were required because of the appearance of $Z$ in both charge balance and exponential terms (e.g. Eqn. 3). For long-term predictive modelling of soil-rain interactions, where large numbers of sequential calculations are required, the CO5NBF routine from the Numerical Algorithms Group Library was used (Numerical Algorithms Group, 1983).

\section{CHOICE OF PARAMETER VALUES}

Values of the fixed CHAOS parameters employed in this study are given in Table 2. Except where indicated, values estimated by Tipping et al., (1988a) for humic acid isolated from the sediment of Mosedale Beck ( a stream in Cumbria, UK) were used. Values of $A c$ and, in proportion, $n$, were changed to rescale the model in fitting data from soil experiments (see below). As will be seen, the chosen values provide reasonable descriptions of the soil data. Given more data all the parameters could be optimized, presumably improving the fit, but for present purposes the values given in Table 2 are adequate.

\begin{tabular}{|c|c|c|}
\hline Parameter & & Value \\
\hline$A c$, total humic acidity, eq $\mathrm{g}^{-1}$ & & $4.78 \times 10^{-3}, 3.01 \times 10^{-3 *}$ \\
\hline$n$, content of $\mathrm{COOH}$ groups, $\mathrm{eq}^{-1}$ & & $2.51 \times 10^{-3}, 1.58 \times 10^{-3 *}$ \\
\hline $\begin{array}{l}\text { Intrinsic equilibrium constants (Table } \\
K_{1} \\
K_{\mathrm{II}} \\
K_{\mathrm{Al}} \\
K_{\mathrm{Al}}, \mathrm{H} \\
K_{\mathrm{Ca}}\end{array}$ & \& Eqns & $\begin{array}{l}2.11 \times 10^{-3} \\
3.42 \times 10^{-5} \\
1.65 \times 10^{-4} \\
1.54 \times 10^{-5}, 2.37 \times 10^{-5 * *} \\
1.63 \times 10^{-7}\end{array}$ \\
\hline $\begin{array}{l}\text { Constants in Eqn. } 6 . \\
\quad P \\
Q\end{array}$ & & $\begin{array}{l}-1680 \\
-870\end{array}$ \\
\hline$V_{B}$, fractional volume of diffuse layer & $\begin{array}{l}0 \cdot 001 \\
0.01 \\
0.5\end{array}$ & $\begin{array}{l}{[\mathrm{HS}] \simeq 2.5 \mathrm{~g} \mathrm{l}^{-1}, I=0.05 \mathrm{~mol} \mathrm{l}^{-1}} \\
{[\mathrm{HS}] \simeq 2.5 \mathrm{~g} \mathrm{l}^{-1}, I=0.003 \mathrm{~mol} \mathrm{l}^{-1}} \\
{[\mathrm{HS}]=70 \mathrm{~g} \mathrm{l}^{-1}, I=0.0003 \mathrm{moll}^{-1}}\end{array}$ \\
\hline
\end{tabular}

The most problematic parameter for assignment of values is $V_{D}$, the fractional diffuse layer volume. The values chosen are crude approximations based on notional humic specific surface areas of $\sim 500 \mathrm{~m}^{2} \mathrm{~g}^{-1}$, combined with the Debye-Hückel parameter (Shaw, 1970). Calculations showed

Table 2. Values of parameters used in CHAOS

*The first value in each pair is for isolated Mosedale Beck humic acid, the second is estimated for soils in the present work (see text).

**First value is for $10^{\circ} \mathrm{C}$, second for $16^{\circ} \mathrm{C}$. Other equilibrium constants are assumed to be temperature-independent (Tipping et al, 1988a). 
however, that rather large tolerances can be placed on $V_{D}$ : for the cases shown in Table 2 referring to (HS) $\simeq 2.5 \mathrm{~g}^{-1}, V_{D}$ could be halved or doubled without markedly affecting cation distributions. For $[\mathrm{HS}]=70 \mathrm{~g}^{-1}$, values of $V_{D}$ in the range $0.3-0.7$ gave reasonably similar results; calculated cation concentrations varied by less than a factor of 2 , except $\left[\mathrm{Al}^{3+}\right]$ in compartment $D$ which varied by up to a factor of 3 . It should be noted that at $[\mathrm{HS}]=70 \mathrm{~g}^{-1}$, the estimated typical field value (see below), overlapping of diffuse layers is likely, so that the assignment of $V_{D}$ becomes more uncertain. The major influence of $V_{D}$ is in determining the proportions of charge-neutralizing cations in the diffuse layer; lowering $V_{D}$ increases the concentrations of the more highly-charged ions at the expense of those of ions of lower charge and vice versa.

Equilibrium constants and enthalpy values of hydrolysis reactions of Al were as listed by Tipping et al. (1988b). Activity coefficients were calculated with the extended Debye-Hückel equation.

\section{EXPERIMENTAL}

Mosedale is a glaciated valley in Cumbria, UK (Nat. grid SD 240030), with a flushed bog in its central part. The vegetation consists largely of Nardus grass, Pteridium bracken and Sphagnum moss. The underlying rocks are of the Borrowdale Volcanic Series. Four soil samples $(A-D)$ were taken from the edges of the bog, a fifth $(E)$ from the waterlogged part. Material from the top $10 \mathrm{~cm}$ of the soil was taken. The samples were dark brown or black.

Water contents of unsieved soil were determined by loss in weight on drying at $100^{\circ} \mathrm{C}$. The remainder of the work was done on material that had been passed, wet, through a $2 \mathrm{~mm}$ sieve. Organic contents were estimated by loss on ignition at $550^{\circ} \mathrm{C}$. Contents of humic substances were estimated by extraction with $\mathrm{NaOH}$ as follows. Soil was suspended at a concentration of ca. $1 \mathrm{~g}$ (dry weight equivalent) $1^{-1}$ in $0.01 \mathrm{M} \mathrm{NaOH}$, the suspension was mixed end-over-end for $24 \mathrm{~h}$, centrifuged and the supernatant solution analysed for dissolved organic carbon using a Phase Separations Tocsin II instrument. The solid residue was re-suspended in $0.01 \mathrm{M} \mathrm{NaOH}$ and the procedure repeated, the second extraction yielding $10 \%$ extra dissolved organic carbon. Estimates of the total amount of $\mathrm{Al}$ in compartments $H, D$ and $S$ were made by extracting for $24 \mathrm{~h}$ with $0.01 \mathrm{M} \mathrm{HNO}_{3} / 0.1 \mathrm{M}$ $\mathrm{NaNO}_{3}$, followed by analysis of the solution phase with pyrocatechol violet (Dougan \& Wilson, 1974). Soil $\mathrm{pH}$ was determined on the solution phase obtained after adding $50 \mathrm{~cm}^{3}$ of $10^{-3} \mathrm{M} \mathrm{NaCl}$ to $50 \mathrm{~g}$ of soil and equilibrating for $24 \mathrm{~h}$.

Batch titration experiments on the soils (which had been neither washed nor allowed to dry out) were performed as follows. Aqueous suspensions of concentration 6-11 g dry weight (equivalent) $1^{-1}$ were prepared and $9 \mathrm{~cm}^{3}$ aliquots placed in polycarbonate centrifuge tubes of $12 \mathrm{~cm}^{3}$ capacity. Known amounts of acid $\left(\mathrm{HNO}_{3}\right)$ or base $(\mathrm{NaOH})$ and of neutral salt $\left(\mathrm{NaNO}_{3}\right)$ were added to each tube and the suspension volumes made up to $10 \mathrm{~cm}^{3}$. The suspensions were allowed to equilibrate by end-over-end mixing for $24 \mathrm{~h}$ at $16 \pm 2^{\circ} \mathrm{C}$, after which the solid and solution phases were separated by centrifugation and the supernatant analysed for $\mathrm{pH}$, monomeric $\mathrm{Al}$ and absorbances at 340 and $600 \mathrm{~nm}$.

Measurements of $\mathrm{pH}$ were made using a Radiometer PHM82 pH meter and GK2401C combination electrode, calibrated with buffers of $\mathrm{pH} 4.00$ and 6.90 , and with solutions of $\mathrm{HNO}_{3}$ of known concentration and ionic strength ( $\mathrm{pH} 3-4.5)$. Monomeric aluminium in solution $\left(\mathrm{Al}_{\mathrm{m}}\right)$ was determined as described by Seip et al. (1984). Absorbance values at $340 \mathrm{~nm}$ (used to estimate HS in solution) were corrected for turbidity by making measurements at both 340 and $600 \mathrm{~nm}$. The following equations hold:

$$
\begin{aligned}
& A_{340}(\text { obs })=A_{340}(H S)+A_{340} \text { (turbidity) } \\
& A_{600}(\text { obs })=A_{600}(H S)+A_{600} \text { (turbidity) }
\end{aligned}
$$

from which we obtain

$$
A_{340}(H S)=\frac{A_{340}\left(o b s-\beta A_{600}(o b s)\right.}{1-(\beta / a)}
$$


where $a=\mathrm{A}_{340}$ (HS) $/ \mathrm{A}_{600}$ (HS) and $\beta=\mathrm{A}_{340}$ (turbidity) $/ \mathrm{A}_{600}$ (turbidity). A value of $a$ was obtained from measurements on filtered coloured supernatants, $\beta$ was estimated from measurements on uncoloured turbid supernatants. Values of $A_{340}$ (turbidity) varied from $0-0.3(1 \mathrm{~cm}$ cell), those of $A_{340}$ (HS) from 0 to 1.2. Humic concentrations were estimated from $A_{340}$ (HS) using an extinction coefficient of $151 \mathrm{~g}^{-1} \mathrm{~cm}^{-1}$, determined for isolated Mosedale Beck humic acid.

The chemical speciations of $\mathrm{Al}_{\mathrm{m}}$ in the supernatants were estimated assuming the only significant species present to be $\mathrm{Al}^{3+}$, its monomeric hydrolysis products and organic complexes. Distributions among these forms were calculated as described by Tipping et al. (1988a) using organic complexation model III. Parameter values for isolated Mosedale Beck humic acid were employed for preliminary calculations. Speciations were refined after rescaling of $A c$ (cf. Table 2) as described below.

\section{RESULTS}

Analytical information on the soil samples is given in Table 3. Each is high in organic matter, and approximately one-quarter of the dry weight consists of $\mathrm{NaOH}$-extractable $\mathrm{HS}$. The $\mathrm{Al}$ contents are assumed to represent metal complexed by the HS, present in the diffuse double layer, and in the bulk soil solution, but not to include $\mathrm{Al}$ in aluminosilicate mineral phases. The $\mathrm{Al}$ contents are similar to values published for organic soils by Cronan et al. (1986), determined by extraction with $\mathrm{CuCl}_{2}$. In attempting to model solid-solution interactions, organic matter not extractable by $\mathrm{NaOH}$ is assumed inert, and all the $\mathrm{Al}$ extractable with $0.01 \mathrm{M} \mathrm{HNO}_{3} / 0.1 \mathrm{M} \mathrm{NaNO}$ is assumed to be monomeric.

Table 3. Analytical data on soil samples

\begin{tabular}{|c|c|c|c|c|c|}
\hline \multirow[b]{2}{*}{ Sample } & \multirow[b]{2}{*}{$\mathrm{pH}^{*}$} & \multirow[b]{2}{*}{$\begin{array}{c}\text { Water } \\
(\%)\end{array}$} & \multicolumn{3}{|c|}{ Analyses on dry weight basis } \\
\hline & & & $\begin{array}{c}\text { Organic } \\
\text { matter } \\
(\%)\end{array}$ & $\begin{array}{c}\text { Humic } \\
\text { substances** } \\
(\%)\end{array}$ & $\begin{array}{c}\text { Aluminium } \\
\left(\mu \mathrm{mol} \mathrm{g}^{-1}\right)\end{array}$ \\
\hline A & 3.7 & 77 & 80 & 23 & 119 \\
\hline B & 4.0 & 72 & 61 & 28 & 154 \\
\hline $\mathrm{C}$ & 3.7 & 86 & 87 & 29 & 54 \\
\hline D & 4.0 & 78 & 72 & 19 & 105 \\
\hline $\mathrm{E}$ & 3.3 & 80 & 85 & 24 & 20 \\
\hline
\end{tabular}

\footnotetext{
*After adding $50 \mathrm{~cm}^{3} 10^{-3} \mathrm{M} \mathrm{NaCl}$ to $50 \mathrm{~g}$ wet soil.

**Calculated from $\mathrm{NaOH}$-extractable organic carbon by assuming HS to be $50 \% \mathrm{C}$.
}

The results of batch titration experiments with the soil samples are presented in Figs $2 \& 3$. Concentrations of inorganic monomeric $\mathrm{Al},\left[\mathrm{Al}_{\mathrm{m}}\right.$-inorg], in the supernatant solutions were calculated from total, i.e. inorganic + organic monomeric, concentrations as described above. Data for $\mathrm{pH} \geqslant 5$ were ignored in order to be able to neglect carbonate equilibria: this meant the rejection of seven of the 90 data points obtained. Further data points were rejected if a substantial proportion $(>20 \%)$ of the monomeric $\mathrm{Al}$ in solution was calculated to be present as organically-complexed $\mathrm{Al}$. This was a precaution against errors in the calculated concentrations of organically-complexed $\mathrm{Al}_{\mathrm{m}}$ causing corresponding errors in the calculated concentrations of inorganic $\mathrm{Al}_{\mathrm{m}}$, and thence in the calculated activity of aluminium, $\left\{\mathrm{Al}^{3+}\right\}$. Such errors would be more serious the greater the proportion of $\mathrm{Al}_{\mathrm{m}}$ present as organic complexes. 


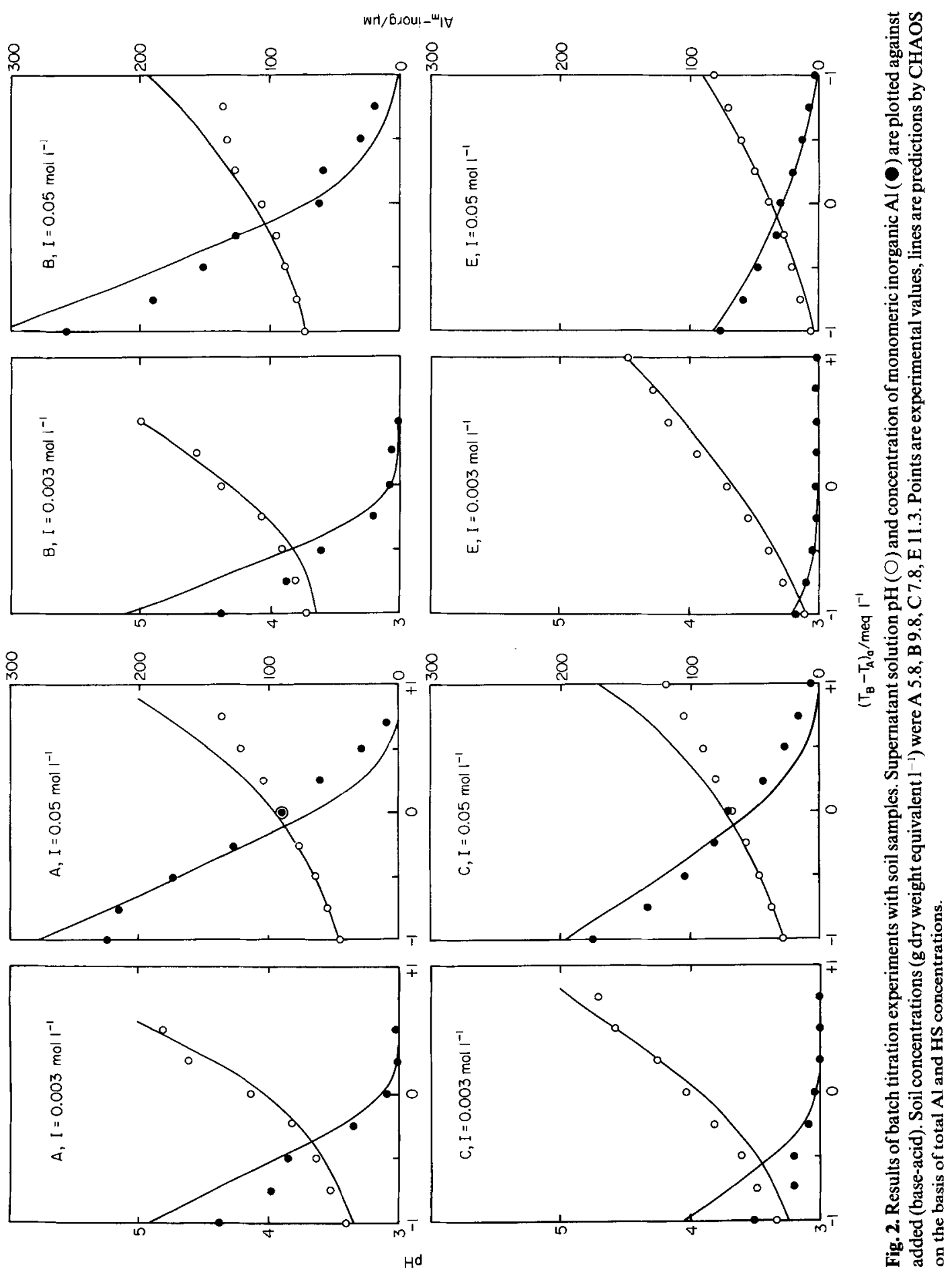



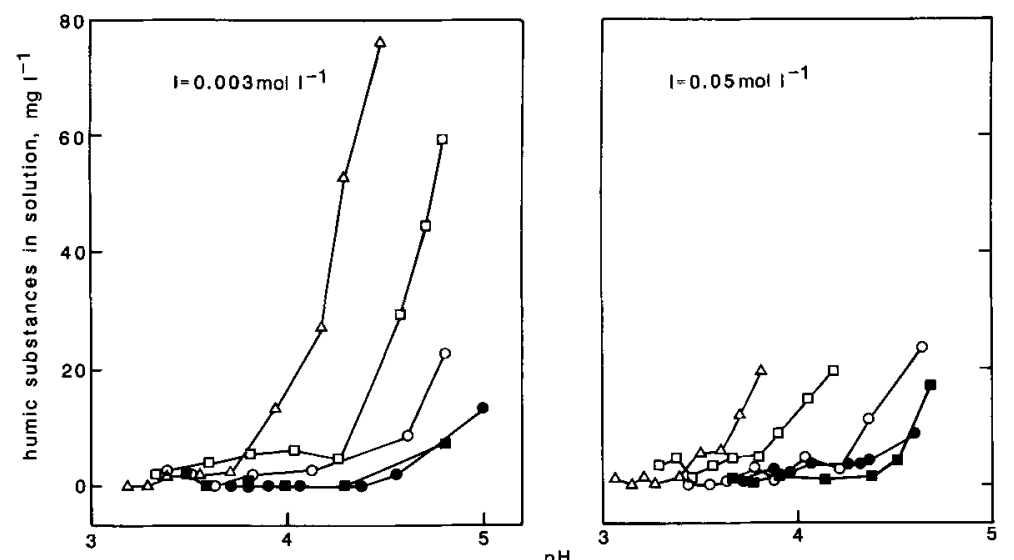

Fig. 3. Concentrations of HS in supernatant solutions plotted against pH for soils $A(O), B(O), C(\square), D(\square)$ and $\mathbf{E}(\triangle)$, at two ionic strengths.

In order to apply CHAOS to the remaining data (65 points), the parameter $A C$ was adjusted. Values of $\left\{\mathrm{Al}^{3+}\right\}$ and $\mathrm{pH}$ were used to calculate ionic distributions and for each data point the value of $A c$ was found for which the total calculated Al was equal to the analytically-determined value (cf. Table 3). While adjusting $A c$, the proportion of humic carboxyl groups was kept constant, i.e. the parameter $n$ was also adjusted so that the ratio $n / A c$ remained the same as in the isolated HS. In effect, this means that we found the concentration of 'active HS' in the soil samples. The results of the calculations are summarized in Table 4 . It is seen from the tolerably small standard deviations that the calculated individual values of $A c$ are reasonably constant for a given soil, and further that $A c$ varied little among soils. The overall mean value of $A c$ is 0.63 times that estimated for isolated Mosedale Beck humic acid. Possible reasons for the difference are (a) that the soil HS have fewer functional groups per gram than the stream bed material, (b) that the soil suspensions contain a competitor (with $\mathrm{H}^{+}$and $\mathrm{Al}^{3+}$ ) for humic binding sites, e.g. iron, (c) that the $\mathrm{HS}$ in the soil are incompletely solvated so that not all the humic functional groups are available for complexation, (d) that there is in fact no difference in $A c$ values, but other model parameters require adjustment. In any event we consider that decreasing $A c$ to 0.63 times the 'starting value' is a relatively minor adjustment. The values of $n$ obtained correspond to approximately $40 \mathrm{meq} \mathrm{g}^{-1}$ soil, of similar magnitude to acidity values of organic soils estimated by titration to an arbitrary neutral $\mathrm{pH}$ value (Bache 1984).

Having obtained a mean $A c$ for each soil, the dependence of $\left[\mathrm{Al}_{\mathrm{m}}\right.$-inorg] and $\mathrm{pH}$ on the concentrations of added acid or base could be calculated, although this requires an estimate of the concentration of mineral acid or base present before any additions were made. We can write

$$
\left(T_{\mathrm{B}}-T_{\mathrm{A}}\right)=\left(T_{\mathrm{B}}-T_{\mathrm{A}}\right)_{o}+\left(T_{\mathrm{B}}-T_{\mathrm{A}}\right)_{a}
$$

where $\left(T_{\mathrm{B}}-T_{\mathrm{A}}\right)$ is the actual difference in total base and acid concentrations, $\left(T_{\mathrm{B}}-T_{\mathrm{A}}\right)_{o}$ is the difference before any additions, and $\left(T_{\mathrm{B}}-T_{\mathrm{A}}\right)_{a}$ is the difference in added base and acid. First it was assumed that $\left(T_{\mathrm{B}}-T_{\mathrm{A}}\right)_{o}$ was zero, then [A $\mathrm{L}_{\mathrm{m}}$-inorg] and $\mathrm{pH}$ were calculated from $T_{\mathrm{Al}}, T_{\mathrm{HS}}$ (total concentrations of $\mathrm{Al}$ and $\mathrm{HS}$, respectively) and $\left(T_{\mathrm{B}}-T_{\mathrm{A}}\right)_{a}$. Next, plots of [ $\mathrm{Al}_{\mathrm{m}}$-inorg] and $\mathrm{pH}$ against $\left(T_{\mathrm{B}}-T_{\mathrm{A}}\right)_{a}$ were constructed and compared with the experimental points. The value of $\left(T_{\mathrm{B}}-T_{\mathrm{A}}\right)_{o}$ was taken to be the average difference between points of the same $\left[\mathrm{Al}_{\mathrm{m}}\right.$-inorg] or $\mathrm{pH}$ (see Table 4). This enabled the calculated plots and experimentally-determined points to be matched (Fig. 2). It is seen that the model reproduces reasonably well the experimental results, bearing in mind that only one parameter $(A C)$ has been adjusted. With more extensive data for soils, comprehensive parameter optimization could be carried out, presumably resulting in improved fits. However, the present analysis demonstrates that CHAOS is a useful model for organic soils. 
Table 4. Calculated values of $A C$ (mean and SD) and of $\left(T_{\mathrm{B}}-T_{\mathrm{A}}\right)_{o}($ see text)

\begin{tabular}{lccc}
\hline Soil & $\begin{array}{c}\text { No. of data } \\
\text { points }\end{array}$ & $\begin{array}{c}\text { Mean } A c \\
\left(\mathrm{meq} \mathrm{g}^{-1}\right)\end{array}$ & $\begin{array}{c}\left(T_{\mathrm{B}}-T_{\mathrm{A}}\right)_{o} \\
\left(\mu \mathrm{mol} \mathrm{l} \mathrm{l}^{-1}\right)\end{array}$ \\
\hline A & 12 & $3.57(0.34)$ & -20 \\
B & 14 & $2.98(0.22)$ & +150 \\
C & 12 & $2.31(0.28)$ & +130 \\
D & 13 & $3.01(0.15)$ & -30 \\
E & 14 & $3.15(0.45)$ & +210 \\
all & 65 & $3.01(0.50)$ & - \\
\hline
\end{tabular}

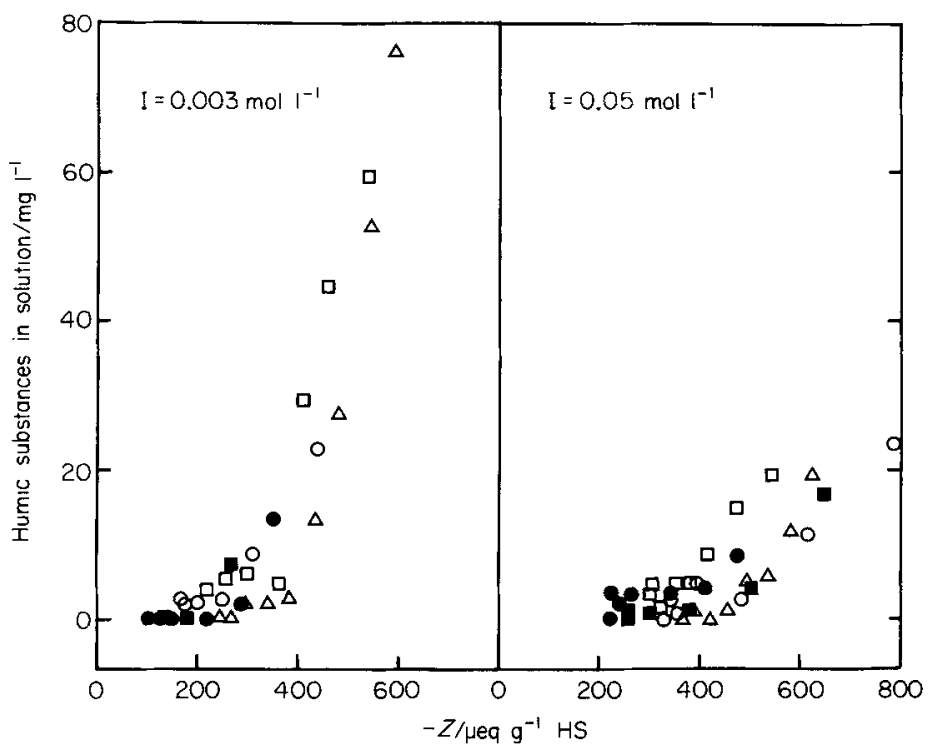

Fig. 4. Data in Fig. 3 plotted against calculated values of $Z$, the net humic charge. Symbols as for Fig. 3.

The experiments with the soil samples provide an opportunity to consider the solubilization of HS in terms of net humic charge, $Z$. It is well known that the fewer protons or metal ions are bound by HS, the greater is their solubility (Hayes \& Swift, 1978). This is illustrated by the plots in Fig. 3 which show increasing amounts of HS in solution as the $\mathrm{pH}$ increases, the effect being more marked the lower the Al/HS ratio (see Table 3). The results for the five soils can be made more-or-less coincident by plotting [HS] in solution against $Z$ calculated using CHAOS (Fig. 4), indicating that concentrations of $\mathrm{HS}$ in soil solution could be quantitatively predicted on the basis of extents of complexation by protons and metal ions. This finding bears out work with aquatic HS (Tipping $e$ t al., 1988a).

\section{PREDICTIVE CALCULATIONS}

In this section we consider the use of CHAOS to predict the compositions of solutions in contact with organic soils. Ionic distributions are calculated for a hypothetical soil subjected to inputs of 
rain of different composition, and the times taken to change from one set of conditions to another are examined. The calculation procedure involves the stepwise replacement of the solution in compartment $S$ by fresh input solution ('rain'), and the computation of the equilibrium distributions of ions at each step. For ease of exposition, it is arranged that steady states can be achieved, by supplying $\mathrm{Al}$ at rates sufficient to keep the total $\mathrm{Al}$ concentration, $T_{\mathrm{Al}}$, constant.

First let us consider an organic soil with a bulk composition representative of those taken from Mosedale (Table 3), with inputs of a simplified 'acid rain' (see Table 5 for composition). The calculated steady state concentrations of species involved are shown in Tables $5 \& 6$, column 1 . The composition of compartment $S$ is seen to be similar to that of the rain, with a small replacement of $\mathrm{H}^{+}$by $\mathrm{Al}^{3+}$ and $\mathrm{AlOH}^{2+}$. The $\mathrm{Al}$ is largely in compartment $H$, i.e. complexed by the HS, whereas the

Table 5. Steady-state ionic distributions. The rain input to soil in columns 1 and 3 had the composition $\mathrm{Ca}^{2+}, 50 \mu \mathrm{M} ; \mathrm{Na}^{+}, 100 \mu \mathrm{M} ; \mathrm{H}^{+}$, $50 \mu \mathrm{M} ; \mathrm{X}^{-}, 250 \mu \mathrm{M}$ : that to soil in columns 2 and 4 had the composition $\mathrm{Ca}^{2+}, 50 \mu \mathrm{M} ; \mathrm{Na}^{+}, 100 \mu \mathrm{M} ; \mathrm{H}^{+}, 10 \mu \mathrm{M}$ and $\mathrm{X}^{-}, 210 \mu \mathrm{M}$. For soil in columns 3 and $4,25 \mu \mathrm{M} \mathrm{Ca}{ }^{2+}$ from rain was assumed to be taken up by plants in exchange for $50 \mu \mathrm{M} \mathrm{H} \mathrm{H}^{+}$. 'Compensating cations' are those in compartment $D$; the percentages refer to the contribution of each cation to countering the charge on the humic substances

\begin{tabular}{|c|c|c|c|c|}
\hline \multirow[b]{2}{*}{ Component } & \multicolumn{4}{|c|}{ Column } \\
\hline & 1 & 2 & 3 & 4 \\
\hline \multicolumn{5}{|l|}{ Soil } \\
\hline$T_{\mathrm{HS}}\left(\mathrm{g}^{-1}\right)$ & 70 & 70 & 70 & 70 \\
\hline $\left.\mathbf{T}_{\mathrm{Al}}\right)$ & 25000 & 25000 & 25000 & 25000 \\
\hline $\left.\mathbf{T}_{\mathrm{Ca}}\right\}(\mu \mathrm{M})$ & 6520 & 14400 & 2250 & 4110 \\
\hline $\left.\mathrm{T}_{\mathrm{Na}}\right\}$ & 850 & 1150 & 715 & 950 \\
\hline \multicolumn{5}{|l|}{ Compartment $H$} \\
\hline Al ? & 336 & 355 & 309 & 318 \\
\hline $\mathrm{Ca}\}(\mu \mathrm{mol} \mathrm{g} \mathrm{HS})$ & 2 & 33 & 0.3 & 0.8 \\
\hline \multicolumn{5}{|l|}{ Compartment $D$} \\
\hline $\mathrm{Al}^{3+} \quad$ & 3000 & 235 & 6700 & 5430 \\
\hline $\mathrm{AlOH}^{2+}$ & 13 & 4 & 18 & 18 \\
\hline $\left.\mathrm{Ca}^{2+} \quad\right\}(\mu \mathrm{M})$ & 12700 & 24200 & 4420 & 8100 \\
\hline $\mathrm{Na}^{+}$ & 1590 & 2200 & 1330 & 1800 \\
\hline $\mathrm{H}^{+}$ & 760 & 220 & 1210 & 1030 \\
\hline \multicolumn{5}{|l|}{ Compartment $S$} \\
\hline $\mathrm{Al}^{3+}$ & 0.74 & 0.02 & 2.85 & 0.93 \\
\hline $\mathrm{AlOH}^{2+}$ & 0.05 & 0.01 & 0.10 & 0.05 \\
\hline $\left.\mathrm{CA}^{2+} \quad\right\}(\mu \mathrm{M})$ & 50 & 50 & 25 & 25 \\
\hline $\mathrm{Na}^{+}$ & 100 & 100 & 100 & 100 \\
\hline $\mathrm{H}^{+}$ & 47.7 & 10 & 91.2 & 57.1 \\
\hline $\mathrm{pH}$ & 4.33 & 5.01 & 4.05 & 4.25 \\
\hline Net humic charge $\left(\mu \mathrm{eq} \mathrm{g}^{-1}\right)$ & -263 & -368.0 & -225.0 & -253 \\
\hline \multicolumn{5}{|l|}{ Compensating cations $(\%)$} \\
\hline $\mathrm{Al}^{3+}$ & 24 & 1 & 64 & 46 \\
\hline $\mathrm{AlOH}^{2+}$ & 0 & 0 & 0 & 0 \\
\hline $\mathrm{Ca}^{2+}$ & 69 & 94 & 28 & 46 \\
\hline $\mathrm{Na}^{+}$ & 4 & 4 & 4 & 5 \\
\hline $\mathrm{H}^{+}$ & 2 & 0 & 4 & 3 \\
\hline
\end{tabular}


$\mathrm{Ca}$ and $\mathrm{Na}$ are largely in the diffuse part of the electrical double layer, compartment $D$. The charge on the HS is $-263 \mu \mathrm{eq} \mathrm{g}^{-1}$, probably too low for much humic material to go into solution. Compensation of the humic charge is mainly by $\mathrm{Ca}^{2+}$ and $\mathrm{Al}^{3+}$ (in compartment $D$ ).

The concentration of $\mathrm{Al}^{3+}$ in the soil solution is calculated to be approximately $1 \mu \mathrm{M}$. This is in reasonable agreement with field observations. For example, Nilsson \& Bergkvist (1983) reported mean values of $\left[\mathrm{Al}^{3+}\right]$ of 0.3 to $8 \mu \mathrm{M}$ for soil waters of $\mathrm{pH} 3.76-4.24$, Driscoll et al. (1985) found $\left[\mathrm{Al}^{3+}\right] \simeq 0.2$ to $5 \mu \mathrm{M}$ for a $\mathrm{pH}$ range of $3.62-4.95$, Cronan et al. $(1986)$ found $\left[\mathrm{Al}^{3+}\right] \simeq 0.1$ to $10 \mu \mathrm{M}$ for $\mathrm{pH} 3.6-4.0$. As pointed out by the last-named authors, these concentrations are considerably lower than would be expected for equilibrium with an aluminium hydroxide phase, for which $\left[\mathrm{Al}^{3+}\right] \sim 100 \mu \mathrm{M}$ might be found at $\mathrm{pH} 4.3$. As with the $\mathrm{Al} /$ humic adsorption model of Cronan et al. (1986), CHAOS explains the undersaturation by interactions with soil HS. When high concentrations of $\mathrm{Al}$ are found in organic soil solutions this is due to organically-complexed Al (David \& Driscoll, 1984).

Now let us consider the effect of reducing the rain acidity by $80 \%$, to give a rain $\mathrm{pH}$ of 5.01 . For the same soil the ionic distributions are given in Tables $5 \& 6$, column 2 . As expected, the pH of the soil solution is very similar to that of the rain, the Al concentration in compartment $S$ now being very small. The humic charge, now compensated for almost entirely by $\mathrm{Ca}^{2+}$, is considerably increased compared to the 'acid rain' steady state, and is probably sufficiently great for HS to pass into solution. Thus, one consequence of reducing rain acidity might be to raise the concentration of dissolved organic matter in soil water. There is palaeolimnological evidence that the reverse process, i.e. diminution of dissolved organic matter concentrations, accompanied acidification (Davis et al., 1985).

Table 6. Cation distributions and base saturations for the steady-states of Table 5. To calculate cation equivalents per $\mathrm{g}$ of soil, it was assumed that HS comprise $25 \%$ of the soil dry weight (cf. Table 3). The apparent base saturation was calculated by assuming that the conventionally-estimated cation exchange capacity would be equivalent to $n$, i.e. $1.58 \mathrm{meq} \mathrm{g}^{-1} \mathrm{HS}$ or $0.395 \mathrm{meq} \mathrm{g}^{-1}$ soil, and dividing this into the sum of the equivalents of $\mathrm{Ca}^{2+}$ and $\mathrm{Na}^{+}$in compartment $D$. The 'base saturation in terms of $Z$ ' was calculated by considering the contributions of $\mathrm{Ca}^{2+}$ and $\mathrm{Na}^{+}$in compartment $D$ to the balancing of charge in compartment $H$

\begin{tabular}{|c|c|c|c|c|c|}
\hline \multirow[b]{2}{*}{ Constituent } & \multirow[b]{2}{*}{ Compartment } & \multicolumn{4}{|c|}{$\begin{array}{c}\text { Composition }\left(\mu \mathrm{eq} \mathrm{g}^{-1} \text { soil) }\right. \\
\text { column }\end{array}$} \\
\hline & & 1 & 2 & 3 & 4 \\
\hline \multirow[t]{4}{*}{ Al } & $H$ & 252.0 & 267.0 & 232.0 & 239.0 \\
\hline & $D$ & 16.0 & 1.0 & 36.0 & 29.0 \\
\hline & $S$ & 0.0 & 0.0 & 0.0 & 0.0 \\
\hline & total & 268.0 & 268.0 & 268.0 & 268.0 \\
\hline \multirow[t]{4}{*}{$\mathrm{Ca}$} & $H$ & 1.0 & 16.5 & 0.2 & 0.4 \\
\hline & $D$ & 45.3 & 86.4 & 15.8 & 28.9 \\
\hline & $S$ & 0.2 & 0.2 & 0.1 & 0.1 \\
\hline & total & 46.5 & 103.1 & 16.1 & 29.4 \\
\hline \multirow[t]{4}{*}{$\mathrm{Na}$} & $H$ & 0.0 & 0.0 & 0.0 & 0.0 \\
\hline & $D$ & 2.8 & 3.9 & 2.4 & 3.2 \\
\hline & $S$ & 0.2 & 0.2 & 0.2 & 0.2 \\
\hline & total & 3.0 & 4.1 & 2.6 & 3.4 \\
\hline \multicolumn{2}{|c|}{ Apparent base saturation (\%) } & 12.0 & 23.0 & 5.0 & 8.0 \\
\hline \multicolumn{2}{|c|}{ Base saturation in terms of $Z(\%)$} & 73.0 & 98.0 & 32.0 & 51.0 \\
\hline
\end{tabular}




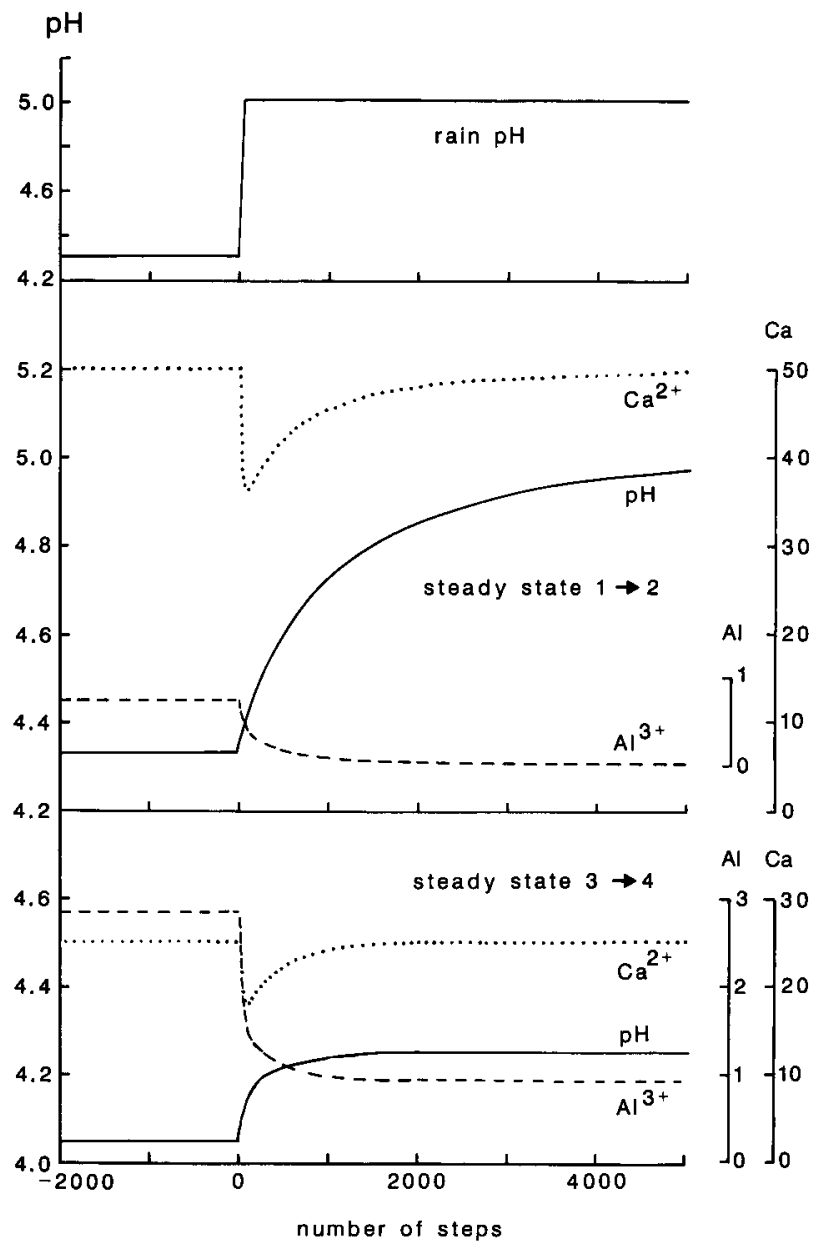

Fig. 5. Predictions of soil solution composition (compartment $S$ ) during conversion between steady states (see

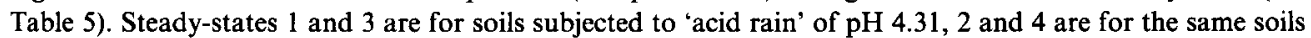
subjected to 'rain' of pH 5.01 . For a $10 \mathrm{~cm}$ depth of soil and rainfall of $2 \mathrm{~m} \mathrm{a}^{-1}, 1000$ steps represent ca. 20 years. Concentrations of $\mathrm{Al}$ and $\mathrm{Ca}$ are $\mu \mathrm{M}$.

In columns 3 and 4 of Tables $5 \& 6$, ionic distributions are given for situations in which acid is imparted to the soil by the exchange of rain $\mathrm{Ca}^{2+}$ for $\mathrm{H}^{+}$, as a result of plant growth (cf. van Breemen et al., 1984). Comparison with the values in columns 1 and 2 shows that the additional acid input causes decreases in $\mathrm{pH}$ and increases in $\left[\mathrm{Al}^{3+}\right]$ in the soil water, lowers the humic charge, and lessens the effect of reducing rain acidity.

Now let us consider how long it takes for one steady-state to change to another. Calculations for conversions between the steady-states referred to in Tables 5 and 6, are presented in Fig. 5. In each case the change in rain composition is assumed to take place over 50 steps (typically equivalent to 1 year-see below). The plots in Fig. 5 show that changes in soil solution composition lag considerably behind the change in the rain, and that the conversion from steady-state 3 to steady-state 4 requires fewer steps than that from 1 to 2 . Although the steady-state concentrations of $\mathrm{Ca}^{2+}$ in compartment $S-\left[\mathrm{Ca}^{2+}\right]_{S}$ are the same for 'acid' and 'less-acid' rain, sharp decreases in $\left[\mathrm{Ca}^{2+}\right]_{S}$ are predicted to occur immediately following the change in rain composition. These decreases are the immediate response to the lower value of $\left[\mathrm{X}^{-}\right]_{S}$, which is ultimately compensated for by lower $\left[\mathrm{H}^{+}\right]_{S}$ and $\left[\mathrm{Al}^{3+}\right]_{S}$. 
How do the steps in the calculations relate to real time? For a soil with a volume of replaceable water of $w \mathrm{~m}^{3}$ per $\mathrm{m}^{2}$, subjected to rainfall of $r \mathrm{~m} \mathrm{a}^{-1}$ the residence time of the water, assuming all of it to infiltrate, and with no evapotranspiration, is $w / r$ a. For a soil depth of $10 \mathrm{~cm}$, and a soil water content of $80 \%$ by volume of which half is replaceable, $w=0.04 \mathrm{~m}$. The residence time for $r=2 \mathrm{~m} \mathrm{a}^{-1}$ is, therefore, 0.02 a, so that 50 calculation steps represent 1 year of rain-soil interaction. Referring to Fig. 5 we see that to pass from one steady-state to another would take tens to hundreds of years for these conditions. Conversions in the opposite direction (less acid $\rightarrow$ acid; $2 \rightarrow 1,4 \rightarrow 3$ ) are calculated to require similar time periods. The changes would be proportionately quicker for thinner soils, slower for deeper ones.

\section{CONCLUSIONS}

The finding that CHAOS accounts quite well for the results of the laboratory experiments encourages the belief that mechanistically-based, quantitative descriptions of ion-binding in organic soils are possible, and that humic solubility may also be predictable. There is, of course, scope for development and improvement. Probably the most simplified features of the model are first the use of the Donnan equilibrium, combined with the semi-arbitrary assignment of values of $V_{\mathrm{D}}$, to describe distributions of ions between the diffuse double layer and the bulk solution, and second the restricted formulation of the abundances and types of ion-binding sites. More realistic descriptions of these could certainly be obtained, although not without introducing more parameters. Further testing of the model on more soil samples and on isolated humic substances is required to find out if such improvements are needed. It may also be desirable to fit experimental data by optimizing all the parameters, rather than simply adjusting the contents of humic functional groups ( $A c$ and $n$ in proportion) as done in the present work.

Calculations with CHAOS (Tables $5 \& 6$, Fig. 5) suggest that, although acidified organic soils will respond to reductions in depositional acidity, the full response may require quite long timeperiods. However, signs of 'improvement' (noticeable decreases in $\left[\mathrm{Ca}^{2+}\right]_{S},\left[\mathrm{Al}^{3+}\right]_{S}$ and $\left[\mathrm{H}^{+}\right]_{S}$ ) could be expected on shorter time-scales. It is also predicted that soils are rather finely-poised with regard to concentrations of HS in solution, and that concentrations might increase following a reduction in rainfall acidity. This could have important consequences for leaching processes in lower soil horizons and, where organic soils are present in reservoir catchments, for water treatment.

With regard to the last point, a final comment is appropriate. It is sometimes suggested that the dissolution of organic acids acidifies water. If, referring to Fig. 1, we regard the dissolution process as the transfer of a part of compartments $H+D$ (i.e. a humic molecule and its diffuse double layer) to compartment $S$, it is clear that this will not affect the ionic composition of the rest of compartment $S$, except for minor changes due to alterations in humic solvation and/or conformation. The main acidifying effect of $\mathrm{HS}$ is not their dissolution; it is their formation and dissociation. The importance of humic dissolution is in the behaviour of the soil solution when its equilibrium is disturbed. For example, humic-rich solutions are better-buffered against additions of acid or base.

\section{ACKNOWLEDGEMENTS}

We thank M. Hornung (Institute of Terrestrial Ecology, Bangor) and D. G. Kinniburgh (British Geological Survey, Wallingford) for their constructive comments on a draft manuscript. We are grateful to B. James, M. Ohnstad and C. Woof for technical support, and to H. Gardberg for typing the draft and final versions of the manuscript. Financial support came from the Commission of European Communities, the Natural Environment Research Council and the Royal Society Surface Waters Acidification Programme.

\section{REFERENCES}

ARNOLD, P.W. 1978. Surface-electrolyte interactions. The Chemistry of Soil Consituents (eds D. J. Greenland \& M. H. B. Hayes) pp. 355-404. John Wiley \& Sons, Chichester.

BACHE, B.W. 1984. Soil-water interactions. Philo- sophical Transactions of the Royal Society of London B 305, 393-407.

Cronan, C.S., Walker, W.J. \& Bloom, P.R. 1986. Predicting aqueous aluminium concentrations in natural waters. Nature (London) 324, 140-143. 
DAvid, M.B. \& Driscoll, C.T. 1984. Aluminium speciation and equilibria in soil solutions of a Haplorthod in the Adirondack Mountains (New York, U.S.A.). Geoderma 33, 297-318.

DAvis, R.B., ANDERSON, D.S. \& Berge, F. 1985. Palaeolimnological evidence that lake acidification is accompanied by loss of organic matter. Nature (London) 316, 436-438.

Dougan, W.K.\& WILsON, A.L. 1974. The absorptiometric determination of aluminium in water. A comparison of some chromogenic reagents and the development of an improved method. Analyst 99, 413-430.

Driscoll, C.T., van Breemen, N. \& Mulder, J. 1985. Aluminium chemistry in a forested spodosol. Soil Science Society of America Journal 49, 437-444.

HAYES, M.H.B. \& SWIFT, R.S. 1978. The chemistry of soil organic colloids. The Chemistry of Soil Constituents (eds D. J. Greenland \& M. H. B. Hayes) pp. 179-320. John Wiley \& Sons, Chichester.

Krug, E.C. \& Frink, C.R. 1983. Acid rain on acid soil: a new perspective. Science 221, 520-525.

MARTELL, A.E. \& SMITH, R.M. 1977. Critical Stability Constants. Vol. 3. Plenum, New York.

Nilsson, S.I. \& BERGKVIST, B. 1983. Aluminium chemistry and acidification processes in a shallow podzol on the Swedish westcoast. Water, Air, Soil Pollution 20, 311-329.

Numerical Algorithms Group. 1983. NAG Fortran Manual, Mark 11; Numerical Algorithms Group Ltd, Oxford.
PERDUE, E.M. 1985. Acidic functional groups of humic substances. Humic Substances in Soil, Sediment, and Water (eds G. R. Aiken, D. M. McKnight, R. L. Wershaw \& P. MacCarthy) pp. 493-526. John Wiley \& Sons, New York.

SEIP, H. M., Müller, L. \& NAAS, A. 1984. Aluminium speciation: a comparison of two spectrophotometric analytical methods and observed concentrations in some acidic aquatic systems in southern Norway. Water, Air, Soil Pollution 23, 81-95.

SHAw, D.J. 1970. Introduction to Colloid and Surface Chemistry. Butterworths, London.

TANFORD, C. 1961. Physical Chemistry of Macromolecules. John Wiley and Sons, New York.

Thurman, E.M. 1985. Organic Geochemistry of Natural Waters. Nijhoff/Junk, Dordrecht.

TipPING, E., BACKEs, C.A. \& Hurley, M.A. 1988a. The complexation of protons, aluminium and calcium by aquatic humic substances: a model incorporating binding-site heterogeneity and macroionic effects. Water Research 22, 597-611.

Tipping, E., WoOF, C., Backes, C.A. \& OHnstad, M. 1988b. Aluminium speciation in acidic natural waters: testing of a model of Al-humic complexation. Water Research 22, 321-326.

van BreemeM, N., Driscoll, C.T. \& Mulder, J. 1984. Acidic deposition and internal proton sources in acidification of soils and waters. Nature (London) 307, 599-604.

(Received 14 May 1987) 